\title{
The Association of CD4, CD8, and CD4/CD8 Ratio with Thyroid Dysfunction in HIV/AIDS
}

\author{
Sri Mulyani, MI. Diah Pramudianti, Dian Ariningrum
}

Department of Clinical Pathology, Faculty of Medicine, Sebelas Maret University Dr. Moewardi Hospital, Surakarta, Indonesia. E-mail: srimnugroho@gmail.com

\begin{abstract}
Incidence of thyroid dysfunction increases in HIV/AIDS patients. It can be a hypothyroid or hyperthyroid, with subclinical hypothyroid predomination. Thyroid dysfunction is associated with the progression of HIV and low CD4 counts. There has been controversy over how HIV affects thyroid function. Opportunistic infections and HBV/HCV co-infections might increase the probability of thyroid dysfunction. Medication of HIV is also an important factor of thyroid dysfunction. Research shows that the use of ART increases the probability of thyroid dysfunction. This study aimed to analyze the association between CD4 counts, CD8, CD4/CD8 ratio, and HIV RNA viral load with thyroid dysfunction in HIV/AIDS patients. An observational study with a cross-sectional design was conducted from August to September 2020 in Dr. Moewardi Hospital, Surakarta on 60 HIV/AIDS patients. All subjects were 18-60 years old. The research data were analyzed with a $2 \times 2$ test table to determine the Prevalence Ratio (PR) of each variable, then multivariate analysis with logistic regression was continued. The study showed $6.7 \%$ thyroid dysfunction in HIV/AIDS patients, $5 \%$ subclinical hyperthyroidism, and $1.7 \%$ subclinical hypothyroidism. The CD4 counts [PR 13.36 (95\% CI: 1.53-116,65; $p=0.017)$ and CD8 counts [PR 0.91 (95\% CI: $0.02-0.51 ; p=0.032)$ ] significantly associated with thyroid dysfunction in HIV/AIDS patients. CD4 counts $<200$ cells $/ \mathrm{mm}^{3}$ and CD8 counts $\geq 500$ cells $/ \mathrm{mm}^{3}$ were associated with the incidence of thyroid dysfunction in HIV/AIDS patients, while CD4/CD8 ratio and HIV RNA viral load were not associated. CD4 count was not an independent predictor of thyroid dysfunction in HIV/AIDS patients.
\end{abstract}

Keywords: Thyroid dysfunction, HIV/AIDS, CD4, CD8, viral load

\section{INTRODUCTION}

Human Immunodeficiency Virus (HIV) is a disease-causing virus, which causes a weakened immune system. Acquired Immune Deficiency Syndrome (AIDS) consists of symptoms of a disease caused by a weakened immune system due to HIV infection. According to the World Health Organization (WHO), there were 37.9 million HIV/AIDS patients worldwide, comprising 36.2 million adults and 1.7 million children. An estimated 770,000 deaths are caused by HIV. The prevalence of HIV/AIDS in Indonesia is $0.4 \%$ for the age range 15-49years.

Human immunodeficiency virus causes a progressive decrease in T-lymphocyte Cluster of Differentiation (CD) 4 cells, which results in immune system failure, increasing the likelihood of opportunistic infections and the development of cancer cells. ${ }^{1}$ Lymphocyte activation, immune senescence, and co-infection play a role in the failure to obtain a normal CD4:CD8 ratio. Decreased CD4 cell counts, increased CD8, and inversed CD4:CD8 ratio $(<1)$ are found in HIV patients. However, with Antiretroviral Therapy (ART), the CD4:CD8 ratio will be $>1 .^{2}$

Studies have shown an increased incidence of thyroid dysfunction in HIV/AIDS patients (approximately 36\%-37\%) compared to the general population. ${ }^{3}$ Thyroid dysfunction can be either hypothyroid or hyperthyroid, with predominant hypothyroidism. Thyroid dysfunction is associated with further infection rates of HIV and a low CD4 cell count. ${ }^{4}$ There is controversy about how HIV affects thyroid function. Co-infection with chronic hepatitis $B$ or hepatitis $C$ can increase the probability of thyroid dysfunction. ${ }^{5}$ Medications used in HIV patients are an important factor in thyroid dysfunction. Research shows that the use of ART increases the probability of developing thyroid dysfunction. Stavudine can directly interfere with the production and metabolism of thyroid hormones. Long-term administration of stavudine will reduce FT4 levels. ${ }^{6}$ 
The cause of thyroid dysfunction in HIV/AIDS patients remains unclear, although there are several hypotheses, including the presence of autoimmune diseases, HIV infection itself, opportunistic infections, and side effects of drugs. Thyroid abnormalities are associated with disease progression, including severe immunosuppression with high HIV RNA viral load. ' Opportunistic infections known to contribute to thyroid dysfunction include Pneumocystis jiroveci, Coccidioides, Mycobacterium tuberculosis, and Cryptococcus neoformans. This condition will result in thyroid abnormalities with symptoms such as swelling of the thyroid gland, pain, and increased levels of T4. ${ }^{1}$

Symptoms of thyroid dysfunction may be non-specific and overlap with the symptoms of other non-endocrine disorders frequently seen in HIV patients, making a clinical diagnosis of thyroid dysfunction difficult. Thyroid levels and patient condition are closely related, there is a relationship between clinical stage and HIV severity. Hypothyroidism causes fatigue, weakness, dry skin, intolerance to cold, constipation, hoarseness, paresthesias, bradycardia, and decreased tendon reflexes. Hyperthyroidism will result in irritability, intolerance to heat, sweating, moist skin, palpitations, tachycardia, fatigue, weight loss with increased appetite, diarrhea, tremor, muscle weakness, hyperreflexia, and eyelid retraction. Subclinical hyperthyroidism will lead to reduced bone density and an increased risk of atrial fibrillation. ${ }^{9}$ Thyroid hormone is very important for the body's metabolic activities. Thyroid dysfunction can reduce the quality of life of HIV patients. Thyroid dysfunction can increase mortality and morbidity. The need for thyroid screening in HIV patients remains a matter of debate.

\section{METHODS}

This study was an observational analytical research with a cross-sectional approach to analyze the relationship between CD4 cell count, CD8 cell count, CD4/CD8 ratio, HIV RNA viral load, and thyroid dysfunction in HIV/AIDS patients. The research was performed at the Clinical Pathology Laboratory Installation of the Dr. Moewardi Hospital in Surakarta from August to September 2020. The research subjects were selected by consecutive sampling on HIV/AIDS patients seeking treatment at the Dr. Moewardi Hospital Voluntary Counselling and Test (VCT) Outpatient Clinic in Surakarta who underwent laboratory tests at the Dr. Moewardi Hospital Clinical Pathology Laboratory Installation in
Surakarta. The inclusion criteria of research subjects included stage 1-2 HIV/AIDS patients, male and female, aged 18-60 years, and agreed to participate in the study by signing informed consent. Exclusion criteria for study subjects included a history of or currently suffering from thyroid disorders, a history of or currently suffering from malignancy, pregnant or lactating females, and a history of kidney disease.

Precision tests and accuracy tests were carried out before laboratory tests to make sure that the test results can be accounted for. The normality test was used to determine the distribution of the data with the Kolmogorov-Smirnov test. Bivariate analysis was carried out using Fisher's exact test to determine the Prevalence Ratio (PR) and 95\% Confidence Interval (CI). Multivariate logistic regression analysis was performed to analyze the effect of study variables on the occurrence of thyroid dysfunction. Statistical analysis was processed using a computer program, the $p$-value $<0.05$ was significant. This research has been approved by the biomedical research ethics committee of the Dr. Moewardi Hospital in Surakarta with the Number 937/VII/HREC/2020.

\section{RESULTS AND DISCUSSIONS}

The daily precision test (within-day) of TSH, FT4, CD4, and CD8 showed good results, the accuracy-test was also in the range. The baseline characteristics of the study subjects showed that subjects consisted of $33(55 \%)$ male patients and 27 (45\%) female patients (Table 1 ). The mean age of the patients was $39.03 \pm 10.06$ years. The median CD4 count was 361 (11-1561) cells $/ \mathrm{mm}^{3}$, and the median for the CD4/CD8 ratio was 0.38 (0.03-1.47). The mean CD8 count was $1044.47 \pm 515.87$ cells $/ \mathrm{mm}^{3}$. The results of the measurement of TSH and FT4 levels in research subjects obtained an average of $1.78 \pm 1.35$ $\mathrm{IU} / \mathrm{mL}$ for TSH and $15.39 \pm 2.67 \mathrm{pmol} / \mathrm{L}$ for FT4. The thyroid status of the research subjects was 56 (93.3\%) euthyroid.

The characteristics of the research subjects in Table 2 showed that there were 4 (6.7\%) patients with thyroid dysfunction. CD4 count $<200$ cells $/ \mathrm{mm}^{3}$ were found in 11 (18.3\%) patients and CD4 200 cells $/ \mathrm{mm}^{3}$ were found in $49(81.7 \%)$ patients. CD8 count 500 cells $/ \mathrm{mm} 3$ were found in 55 (91.7\%) patients and CD8 count $<500$ cells $/ \mathrm{mm}^{3}$ were found in $5(8.3 \%)$ patients. There was a statistically significant difference in CD4 count $<200$ cells $/ \mathrm{mm}^{3}$ with CD4 count 200 cells $/ \mathrm{mm}^{3}(p=0.002)$ and CD8 count $\geq 500$ cells $/ \mathrm{mm}^{3}$ with CD8 count $<500$ cells $/ \mathrm{mm}^{3} \quad(p=0.002)$ on thyroid dysfunction. CD4/CD8 ratio < 0.3 were obtained in 20 (33.3\%) 
patients and CD4/CD8 ratio of 0.3 were found in 40 (66.7\%) patients. Viral RNA of HIV was detected in 31 (51.7\%) patients but was undetectable in 29 (48.3\%) patients. Opportunistic infection was found in 8 $(13.3 \%)$ patients and co-infection was found in 5 $(8.3 \%)$ patients.

Cut-off values for CD4, CD8, CD4/CD8 ratio was based on previous studies. The cut-off for the CD4 count was 200 cells $/ \mathrm{mm}^{3}$, the CD8 count was 500 cells $/ \mathrm{mm}^{3}$, and the CD4/CD8 ratio was 0.3 . Bivariate analysis between CD4 count $<200$ cells $/ \mathrm{mm}^{3}$ and thyroid dysfunction showed a statistically significant relationship [PR 13.36 (95\% CI: 1.53-116.65; $\mathrm{p}=0.017)$ ]. CD8 count 500 cells $/ \mathrm{mm}^{3}$ with thyroid dysfunction also showed a statistically significant relationship [PR 0.91 (95\% CI: 0.16-0.51; $\mathrm{p}=0.032$ )].

Table 1. The basic characteristic of research subjects

\begin{tabular}{|c|c|c|c|}
\hline Variable & Total $n=60$ & Mean \pm SD & Median (min-max) \\
\hline Age (years) ${ }^{a}$ & & $39.03 \pm 10.06$ & \\
\hline \multicolumn{4}{|l|}{ Gender } \\
\hline Male & $33(55 \%)$ & & \\
\hline Female & 27 (45\%) & & \\
\hline CD4 (cells $\left./ \mathrm{mm}^{3}\right)^{\mathrm{b}}$ & & & $361(11-1561)$ \\
\hline CD8 (cells $\left./ \mathrm{mm}^{3}\right)^{\mathrm{a}}$ & & $1044 \pm 515.87$ & \\
\hline CD4/CD8 ratio ${ }^{b}$ & & & $0.38(0.03-1.47)$ \\
\hline $\mathrm{TSH}(\mu \mathrm{IU} / \mathrm{mL})^{\mathrm{a}}$ & & $1.78 \pm 1.35$ & \\
\hline FT4 $(\mathrm{pmol} / \mathrm{L})^{\mathrm{a}}$ & & $15.39 \pm 2.67$ & \\
\hline \multicolumn{4}{|l|}{ Thyroid } \\
\hline Euthyroid & $56(93.3 \%)$ & & \\
\hline Subclinical Hypothyroid & $1(1.7 \%)$ & & \\
\hline Subclinical Hyperthyroid & $3(5 \%)$ & & \\
\hline
\end{tabular}

Note: SD: Standard Deviation; Min: minimum; Max: maximum; CD: Cluster of Differentiation; TSH: Thyroid Stimulating Hormone; FT4: Free Tetraiodotironin; $\mu \mathrm{IU} / \mathrm{mL}$ : micro international unit per millilitre; pmol/L: picomol per liter; $\mathrm{mm}^{3}$ : millimeter cubic.

a : Data with normal distribution: Mean \pm SD

$\mathrm{b}$ : Data with abnormal distribution: median (min-max)

Table 2. Distribution of research variables based on thyroid dysfunction

\begin{tabular}{|c|c|c|c|c|}
\hline \multirow{2}{*}{ Independent Variable } & \multirow{2}{*}{$\begin{array}{l}\text { Total } \\
n=60\end{array}$} & \multicolumn{2}{|c|}{ Thyroid Dysfunction } & \multirow{2}{*}{$\mathbf{p}$} \\
\hline & & Yes & No & \\
\hline & $(100 \%)$ & $4(6.7 \%)$ & $56(93.3 \%)$ & \\
\hline \multicolumn{4}{|l|}{ Absolute CD4 } & $0.002^{*}$ \\
\hline$<200$ cells $/ \mathrm{mm}^{3}$ & $11(18.3 \%)$ & $3(75 \%)$ & $8(14.3 \%)$ & \\
\hline$\geq 200$ cells $/ \mathrm{mm}^{3}$ & $49(81.7 \%)$ & $1(25 \%)$ & $48(85.7 \%)$ & \\
\hline & $0.002^{*}$ \\
\hline$\geq 500$ cells $/ \mathrm{mm}^{3}$ & 55 (91.7\%) & $2(50 \%)$ & $53(94.6 \%)$ & \\
\hline$<500$ cells $/ \mathrm{mm}^{3}$ & $5(8.3 \%)$ & $2(50 \%)$ & $3(5.4 \%)$ & \\
\hline \multicolumn{4}{|l|}{ CD4/CD8 ratio } & 0.067 \\
\hline$<0.3$ & 20 (33.3\%) & $3(75 \%)$ & 17 (30.4\%) & \\
\hline$\geq 0.3$ & $40(66.7 \%)$ & $1(25 \%)$ & $39(69.6 \%)$ & \\
\hline \multicolumn{4}{|l|}{ Viral load of HIV RNA } & 0.334 \\
\hline Detected & 31 (51.7\%) & $3(75 \%)$ & $28(50 \%)$ & \\
\hline Undetected & $29(48.3 \%)$ & $1(25 \%)$ & $28(50 \%)$ & \\
\hline \multicolumn{4}{|l|}{ Opportunistic infection } & 0.477 \\
\hline Yes & $8(13.3 \%)$ & $1(25 \%)$ & 7 (12.56\%) & \\
\hline No & $52(86.7 \%)$ & $3(75 \%)$ & $49(87.5 \%)$ & \\
\hline \multicolumn{4}{|l|}{ HBV/HCV co-infection } & 0.533 \\
\hline Yes & $5(8.3 \%)$ & $0(0 \%)$ & 5 (8.9\%) & \\
\hline No & $55(91.7 \%)$ & $4(100 \%)$ & $51(91.1 \%)$ & \\
\hline
\end{tabular}

Note: CD: Cluster of Differentiation; HIV: Human Immunodeficiency Virus; RNA: Ribonuclease Acid; HBV: Hepatitis B Virus; HCV: Hepatitis C Virus; $\mathrm{mm}^{3}$ : millimeter cubic; Pearson Chi-Square test * $\mathrm{p}<0.05$ was significant 
Table 3. $2 \times 2$ Table of CD4 count, CD8 count, $C D 4 / C D 8$ ratio, viral load of HIV RNA, and other variables with possible influence on thyroid function

\begin{tabular}{|c|c|c|c|c|c|}
\hline \multirow{2}{*}{ Variable } & \multicolumn{2}{|c|}{ Thyroid Dysfunction } & \multirow{2}{*}{ PR } & \multirow{2}{*}{$\mathrm{CI}$ of $95 \%$} & \multirow{2}{*}{$\mathbf{p}$} \\
\hline & Yes & No & & & \\
\hline \multicolumn{6}{|c|}{ CD4 (cells $/ \mathrm{mm}^{3}$ ) } \\
\hline$<200$ & 3 & 8 & 13.36 & $1.53-116.65$ & $0.017^{*}$ \\
\hline$\geq 200$ & 1 & 48 & & & \\
\hline \multicolumn{6}{|c|}{ CD8 (cells $\left./ \mathrm{mm}^{3}\right)$} \\
\hline$\geq 500$ & 2 & 53 & 0.91 & $0.02-0.51$ & $0.032^{*}$ \\
\hline$<500$ & 2 & 3 & & & \\
\hline \multicolumn{6}{|c|}{ CD4/CD8 ratio } \\
\hline$<0.3$ & 3 & 17 & 6.0 & $0.67-54.07$ & 0.103 \\
\hline$\geq 0.3$ & 1 & 39 & & & \\
\hline \multicolumn{6}{|c|}{ Viral load of HIV RNA } \\
\hline Detected & 3 & 28 & 2.81 & $0.31-25.48$ & 0.332 \\
\hline Undetected & 1 & 28 & & & \\
\hline \multicolumn{6}{|c|}{ Opportunistic infection } \\
\hline Yes & 1 & 7 & 2.0 & $0.32-12.51$ & 0.445 \\
\hline No & 3 & 49 & & & \\
\hline \multicolumn{6}{|c|}{ HBV/HCV co-infection } \\
\hline Yes & 0 & 5 & NA & NA & 0.699 \\
\hline No & 4 & 51 & & & \\
\hline
\end{tabular}

Note: PR: Prevalence Ratio; CI: Confidence Interval; CD: Cluster of Differentiation; $\mathrm{mm}^{3}$ : millimeter cubic; HIV: Human Immunodeficiency Virus; RNA: Ribonuclease Acid; HBV: Hepatitis B Virus; HCV Hepatitis C Virus; NA: Not applicable; Fisher's exact test * $p<0.05$ was significant

Table 3 showed the bivariate analysis between CD4 count, CD8 count and other variables with possible influence of thyroid dysfunction. A statistically significant relationship was found between CD4 count and CD8 count of thyroid dysfunction. This might be due to the CD4 count < $200 \mathrm{cells} / \mathrm{mm}^{3}$ indicating a severe decrease in the immune system and an increase in the occurrence of opportunistic infections. Opportunistic infections are a common complication in HIV/AIDS patients. HIV/AIDS patients with CD4 $<200$ cells $/ \mathrm{mm}^{3}$ have a six times higher susceptibility to opportunistic infections than CD4 counts $>350$ cells $/ \mathrm{mm}^{3}$. The host immune system is an important factor in the occurrence of opportunistic infections. When there is contact with bacterial antigens, cell differentiation and proliferation will be stimulated to form a specific T-cell population. Damage to the immune system will facilitate the occurrence of infection in HIV/AIDS patients. ${ }^{10}$ Research by Muddasir and Shoukat showed a $31 \%$ increase of thyroid dysfunction in CD4 counts $<200$ cells $/ \mathrm{mm}^{3}$, compared to CD4 counts 200 cells $/ \mathrm{mm}^{3}$, which was $24 \% .{ }^{11}$

Bivariate analysis using Fisher's exact test found a statistically significant relationship was found between CD8 count and thyroid dysfunction. An increased $C D 8$ count is a response to acute infection and will continue to increase in HIV/AIDS patients and indicates chronic inflammation in HIV/AIDS patients. ${ }^{12}$ ART therapy can cause a decrease in CD8 count; however, CD8 count will increase again due to chronic inflammation that occurs in HIV/AIDS patients. Helleberg et al. stated that the CD8 count will continue to increase in HIV/AIDS patients and will not return to normal even with CART administration for 10 years. ${ }^{13} \mathrm{An}$ increase in CD8 cell count after long-term ART is associated with an increase in non-AIDS-related mortality. Trickey et al. stated that the CD8 count showed a U-shaped relationship with non-AIDS mortality. ${ }^{14}$ In addition, the lowest mortality rate was around the median CD8 count and the highest mortality rate was found at high $C D 8$ counts.

The relationship between CD4/CD8 ratio and thyroid dysfunction was not statistically significant $(p=0.103)$. The $C D 4 / C D 8$ ratio naturally declines with age and is associated with increased mortality. It also acts as a marker of acute and chronic inflammation. CD8 count and CD4/CD8 ratio are prognostic markers of additional morbidity and mortality in 
HIV/AIDS patients. Although the CD8 count is a marker of chronic inflammation, it has not been able to become a single prognostic marker for non-AIDS mortality in HIV/AIDS patients. ${ }^{12}$

Human immunodeficiency virus infection causes systemic inflammation and changes in proinflammatory cytokine profile, whereas CD8 cell proliferation and differentiation are predominantly regulated by HIV replication and inflammation. Therefore, cytokine changes are important in CD8 cell homeostasis. As one of the main causes of chronic inflammation, intestinal mucosal damage that occurs early in HIV infection will result in changes in microbiota and cytokine production. Lipopolysaccharides (LPS) are recognized by the Toll-Like Receptor (TLR) of dendritic cells leading to the production of IFN. The accumulation of IFN will increase the production of IL-15 and IL-7, which directly results in the expansion of CD8 cells. ${ }^{15}$ This is a factor of a high CD8 count in HIV/AIDS patients. Therefore, despite an increased CD4 count, the $\mathrm{CD} 4 / \mathrm{CD} 8$ ratio remains high, but the $\mathrm{CD} 4 / \mathrm{CD} 8$ remains inversed.

Bivariate analysis showed a statistically significant relationship between CD4 and CD8 counts with the occurrence of thyroid dysfunction in HIV/AIDS patients, although the CD4/CD8 ratio was not statistically significant. This is possible because the different patterns of T-lymphocyte decline and recovery in HIV patients are complex and only partially understood. The timing of initiation of ART therapy can affect not only T-cell counts but also the relative frequency of naive cells, memory cells, and cell activation rates, which may play a role in CD4/CD8 ratio and immune system recovery. Previous studies have shown that a low CD4/CD8 ratio correlates with several markers of inflammation, immune system activation, and immunosenescence. This is possible because the CD4/CD8 ratio can be useful in describing immune dysfunction, not based on CD4 or CD8 counts. Several studies have shown that the CD4/CD8 ratio before ART therapy is more potential as a predictor of immune system recovery. ${ }^{16}$

The association between HIV RNA viral load and thyroid dysfunction was not statistically significant $(p=0.332)$. Viral load is one of the important markers of the success of ART therapy in HIV/AIDS patients. Research by Carvalho et al. in 153 female HIV/AIDS patients on HAART found higher undetectable HIV RNA viral load in the group with thyroid dysfunction. ${ }^{17}$ There is an association between HAART and the development of Autoimmune Thyroid Disease (AITD) because AITD is only found in
HIV/AIDS patients with undetectable HIV RNA viral load and slightly higher CD4 cell counts.

The relationship between opportunistic infections and thyroid dysfunction in HIV/AIDS patients was not statistically significant $(p=0.445)$. This might be due to the small number of HIV/AIDS patients who had opportunistic infections in this study, with a percentage of $13.3 \%$ and this study found tuberculosis as an opportunistic infection of HIV/AIDS patients. Some references mention opportunistic infections, such as Pneumocystis jiroveci, tuberculosis, Coccidiodes and Cryptococcus causing thyroiditis and causing disruption of thyroid function. In addition, drugs given to treat opportunistic infections are a factor in the occurrence of hypothyroidism, such as rifampin, which causes a decrease in peripheral thyroid hormone through microsomal hepatic enzymes. ${ }^{1}$

The association between HBV/HCV co-infection and thyroid dysfunction in HIV/AIDS patients was not statistically significant $(p=0.699)$. A total of $8.3 \%$ patients were co-infected with HBV, and there was no co-infection with HCV. Research by Madeddu et al. in 202 HIV/AIDS patients found a higher number of co-infections with details as follows: 57.1\% HCV co-infection, 1.1\% HBV co-infection, and $1.6 \% \mathrm{HCV}$ and HBV co-infection. ${ }^{18}$ Bongiovanni et al. stated that HBV/HCV co-infection is an important factor influencing HIV progression and the effect of HAART on immune response, liver function, and endocrine function. ${ }^{19}$ Research by Ji et al. found 8 patients from a total of 178 research subjects with $\mathrm{HBV} / \mathrm{HCV}$ co-infection, showing that FT3 and FT4 levels were significantly increased in patients with $\mathrm{HCV}$ co-infection and decreased in HBV infection. ${ }^{5}$ Autoimmune-related $\mathrm{HBV} / \mathrm{HCV}$ and side effects of interferon therapy are potential explanations for thyroid dysfunction in HIV/AIDS patients.

The cause of thyroid dysfunction in HIV patients remains unclear, whether HIV infection itself, complications, therapy, or progression of the disease. ${ }^{20,21}$ Thyroid dysfunction in HIV/AIDS patients has been reported before ART therapy, suggesting that it may be due to opportunistic infections, regional tumors, systemic disease, or energy deprivation. A study by Bongiovanni et al. concluded that antiretroviral therapy had an acute effect on thyroid hormone because patients who had just started antiretroviral therapy showed a higher incidence of subclinical hypothyroidism than patients on one year of antiretroviral therapy. ${ }^{19}$

Regression analysis on CD4 counts and other variable with possible influence on thyroid dysfunction showed in Table 4. The results of the 
Table 4. Results of regression analysis on CD4 counts and other variables with possible influence on thyroid dysfunction

\begin{tabular}{lccc}
\hline Variable & Adjusted PR & CI of 95\% & p \\
\hline Model 1 & & & \\
CD4 count & 9.60 & $0.52-178.14$ & 0.129 \\
CD8 count & 0.30 & $0.02-4.91$ & 0.398 \\
Model 2 & & & \\
CD4 count & 6.43 & $0.16-254.11$ & 0.321 \\
CD8 count & 0.27 & $0.16-4.72$ & 0.371 \\
CD4/CD8 ratio & 1.71 & $0.71-41.29$ & 0.742 \\
\hline
\end{tabular}

Note: PR: Prevalence Ratio; CI: Confidence Interval; CD: Cluster of Differentiation; Backward Regression Logistic test ${ }^{*} p<0.05$ was significant

analysis in model 1 , adjustment for the variable CD8 count, and CD4 count $<200$ cells $/ \mathrm{mm}^{3}$ did not show an association with thyroid dysfunction [PR 9.60 (95\% CI: 0.52-178.14; $p=0.129$ )]. In addition, CD8 count 500 cells $/ \mathrm{mm}^{3}$ also showed no significant relationship with thyroid dysfunction [PR 0.3 (95\% CI: $0.02-4.91 ; p=0.398)]$. The results of the analysis of model 2, adjustment for the variable CD8 count and CD4/CD8 ratio, CD4 count $<200$ cells $/ \mathrm{mm}^{3}$ did not show an association with thyroid dysfunction $(P R=6.43$ (95\% CI: 0.16-254.11; $p=0.321$ ), as well as for the variable CD8 count [PR 0.27 (95\% CI: 016-4.72; $\mathrm{p}=0.371)$ and $\mathrm{CD} 4 / \mathrm{CD} 8$ ratio [PR $1.71(95 \% \mathrm{CI}$ : 0.71-41.29; $p=0.742]$.

Multivariate analysis showed that CD4 $<200$ cells $/ \mathrm{mm}^{3}$ was significantly associated with thyroid dysfunction ( $p=0.017)$; however, after adjusting for other variables that might influence thyroid dysfunction such as CD8 cell count and CD4/CD8 ratio, there was no significant association with thyroid dysfunction. These results indicated that CD4 cell count was not an independent risk factor for thyroid dysfunction in HIV/AIDS patients.

This study found three patients with subclinical hyperthyroidism, different progression of subclinical hyperthyroidism in HIV/AIDS patients, and controversy about the need for therapy. Subclinical hyperthyroidism may progress to hyperthyroidism, or remain stable for a long time, or return to a state of euthyroid. Subclinical hyperthyroidism occurs in HIV/AIDS patients on ART. Therapy will improve the immune system of HIV/AIDS patients and cause the formation of antibodies that will bind to the TSH receptor and trigger cyclic adenosine monophosphate (CAMP) to react continuously resulting in the increased production of thyroid hormone. The increase in hormone occurs because the feedback system via TSH has been blocked by antibodies.

Grave's disease is an autoimmune disease that is often found in HIV/AIDS patients. Antibodies will bind to the TSH receptor, and cause the thyroid gland to be overactive. Subclinical hyperthyroidism can be an early sign of Grave's disease. Symptoms of subclinical hyperthyroidism that appear may include palpitations, anxiety, intolerance to heat, fatigue, and excessive sweating. This can reduce the quality of life, especially for young HIV/AIDS patients. Treatment for subclinical hyperthyroidism remains controversial. ${ }^{9}$

Subclinical hypothyroidism was found in one patient, although it was considered a mild symptom, and generally asymptomatic, this is a sign of changes in the thyroid gland and has the potential to be hypothyroid or an early sign of hypothyroidism. Subclinical hypothyroidism triggers a decrease in systolic function, left ventricular diastolic dysfunction, impaired cardiac vascular muscle relaxation, and arterial stiffness.

The limitations of this study include the use of a cross-sectional study design that this study was unable to confirm a causal relationship between CD4 count, CD8 count, and other variables with thyroid dysfunction in HIV/AIDS patients. A study with a cohort design was needed to obtain a hazard ratio to clarify the relationship between CD4 count, CD8 count, CD4/CD8 ratio, and other variables with thyroid dysfunction in HIV/AIDS patients. This study was not able to determine whether thyroid dysfunction occurred before the patient was diagnosed with HIV/AIDS, because symptoms might not be present, or if the FT4 and TSH tests were never performed before.

\section{CONCLUSIONS AND SUGGESTIONS}

There was a statistically significant relationship between CD4 count and CD8 count with thyroid dysfunction $(p=0.017 ; p=0.032)$, but there was no relationship between CD4/CD8 ratio and HIV RNA viral load with thyroid dysfunction in HIV/AIDS patients. CD4 cell count was not an independent predictor of thyroid dysfunction in HIV/AIDS patients. Further research was needed to determine the relationship between CD4 and CD8 counts with thyroid dysfunction in HIV/AIDS patients, using different cut-off values, study designs, and healthy controls. More complete data such as length of stay with HIV and duration of antiretroviral therapy, and inflammatory status can be added in future studies. Path analysis can be performed to further assess the 
relationship between study variables and the incidence of thyroid dysfunction in HIV/AIDS patients.

\section{REFERENCES}

1. Ibrahim M, Adeniran A, Ibrahim MA, Woodward C, Mital D, Ahmed MH. Thyroid function in individuals living with human immunodeficiency virus: The concern and debate about regular screening. Annals of Thyroid, 2019; 4(12): 1-8.

2. Petoumenos K, Choi JY, Hoy J, Kiertiburanakul S, Ng OT, Boyd M, Rajasuriar $\mathrm{R}$, et al. CD4:CD8 ratio comparison between cohorts of HIV-positive asian and caucasians upon commencement of antiretroviral therapy. Antiviral Therapy, 2017; 22(8): 659-668.

3. Emokpae MA, Akinnuoye IM. Asymptomatic thyroid dysfunction in human immunodeficiency virus-1-infected subjects. J Lab Physicians, 2018; 10(2): 130-134.

4. Indikar M, Shoukat AR. Human immunodeficiency virus and its co-relation with thyroid levels and CD4 count. Journal of Dental and Medical Sciences, 2019; 18(5): 41-46.

5. Ji S, Jin C, Hoxtermann S, Fuchs W, Xie T, et al. Prevalence and influencing factors of thyroid dysfunction in HIV-infected patients. Biomed Research International, 2016; 6: 1-11.

6. Sebastian SA, Sumitthra S, Kurian J, Mathew V, Idiculla JM. Thyroid dysfunction in patients on antiretroviral therapy: A perspective from southern India. Natl Med J India, 2018; 31(3): 136-139.

7. Thongam S, Keithelakpam S, Singh TY, Singh RL, Singh AM, Ranabir S. Thyroid dysfunction in human deficiency virus-infected children and its correlation with CD4 T-lymphocyte count. Indian Journal of Endocrinology and Metabolism, 2015; 19(2): 272-276.

8. Hatzl M, Ollinger A, Geit M, Wieinger K, Angerbauer K, Aubock J, Gabriel M. Thyroid screening in HIV-infected patients with antiretroviral therapy. The Central European Journal of Medicine, 2015; 127(15-16): 601-605.

9. Darmowidjojo B, Antika LD. Subclinical thyroid dysfunction: Diagnosis and management. Ejki, 2018; 6(2): 140-150.

10. Buchacz K, Lau B, Jing Y, Bosch R, Abraham AG, et al. Incidence of AIDS-defining opportunistic infections in a multicohort analysis of HIV-infected persons in the United States and Canada, 2000-2010. J Infect Dis,
2016; 214(6): 862-72.

11. Indikar M, Shoukat AR. Human immunodeficiency virus and its co-relation with thyroid levels and CD4 count. Journal of Dental and Medical Sciences, 2019; 18(5): 41-46.

12. Jenks JD, Hoenigl M. CD4:CD8 ratio and CD8+ cell count for prognosticating mortality in HIV infected patients on antiretroviral therapy. J Lab Precis Med, 2018; 3(8): 1-5.

13. Helleberg M, Kronborg G, Ullum H, Ryder LP, Obel N, Gerstoft J. Course and clinical significance of CD8 T-cell in a large cohort of HIV-infected individuals. The Journal of Infectious Disease, 2015; 211(11): 1726-1734.

14. Trickey A, May MT, Schommers P, Tate J, Ingle SM, et al. CD4:CD8 ratio and CD8 count as prognostic markers for mortality in human immunodeficiency virus-infected patients on antiretroviral therapy: The antiretroviral therapy cohort collaboration (ART-CC). CID, 2017; 65: 959-966.

15. Cao W, Mehraj V, Kaufmann DE, Li T, Routy J. Elevation and persistence of CD8 T-cells in HIV infection: the Achilles heel in the ART era. Journal of the International AIDS Soc, 2016; 19(2): 1-9.

16. Mendez T, Napravnik S, Zakharova O, Kuruc J, Gay C, et al. Acute HIV infection and $\mathrm{CD} 4 / \mathrm{CD} 8$ rasio normalization after antiretroviral therapy initiation. J Acquir Immuno Defic Syndr, 2019; 79(4): 510-518.

17. Madeddu G, Spanu A, Chessa F. Thyroid function in human immunodeficiency virus patients treated with Highly Active Antiretroviral Therapy (HAART): A longitudinal study. Clinical Endocrinology, 2006; 64(4): 375-383.

18. Carvalho LG, Teixeria PF, Panico AL, Cohen MV, Pinheiro MF, Barroso PF, Waisman M. Evaluation of thyroid function and autoimmunity in HIV-infected women. Arq Bras Endocrinol Metab, 2013; 57(6): 450-456.

19. Bongiovanni $M$, Adorni $F$, Casana $M$, Tordato F, Tincati C, Cicconi P, Bini T, et al. Subclinical hypothyroidism in HIV infected subjects. Journal of Antimicrobial Chemotherapy, 2006; 58: 1086-1089.

20. Gafencu M, Bizerea TO, Stroescu RF, Costa R, Marginean O, Doros G. Thyroid dysfunction in an AIDS patient. Acta Endocrinologica, 2017; 13(2): 220-223.

21. Harslof M, Knudden AD, Benfield T, Nordestgaard BG, Rasmussen UF, Nielsen SD. No evidence of increased risk of thyroid dysfunction in well treated people living in HIV. AIDS, 2018; 32: 2195-2199. 